\title{
MARCAS DA CULTURA PROFISSIONAL NA FORMAÇÃO DE PROFESSORES: ANÁLISE NO CONTEXTO DE UM CURSO DE PEDAGOGIA
}

\author{
SIGNATURES OF PROFESSIONAL CULTURE IN TEACHER EDUCATION: \\ ANALYSIS IN THE CONTEXT OF A PEDAGOGY COURSE
}

\author{
Sabryna Raychtock ${ }^{1}$ \\ Giseli Barreto da $\mathrm{Cruz}^{2}$
}

\begin{abstract}
Resumo
Neste artigo focaliza-se pesquisa com oito egressos de um curso de Pedagogia sobre sua visão acerca das marcas da cultura profissional na formação docente. O escopo do trabalho está em analisar os elementos e/ou contextos do curso que favorecem a aproximação entre os estudantes e a profissão. O quadro teórico baseia-se em Shulman (2005), no tocante às três dimensões das marcas pedagógicas profissionais: pensar, atuar e agir com integridade; em diálogo com Silva, Almeida, Gatti (2016) e os seus referentes para a formação docente: conhecimento profissional, prática profissional e engajamento profissional. Metodologicamente, foi analisado o PPC do curso e entrevistados oito recém-egressos. A análise considerou: i- a força/fraqueza das disciplinas; ii- a convivência com professores formadores e suas práticas; iii- o lugar das práticas de ensino. Os achados sugerem que o curso favorece as dimensões do saber e do atuar docente, apenas tangenciando a dimensão do agir com integridade.
\end{abstract}

Palavras-chave: Cultura profissional docente; Formação de professores; Curso de Pedagogia.

\begin{abstract}
This article focuses on research with eight graduates from a Pedagogy course about their vision on the marks of professional culture in teacher education. The scope of the work is to analyze the elements and / or contexts of the course that favor the approximation between students and the profession. The theoretical framework is based on Shulman (2005), regarding the three dimensions of professional pedagogical marks: to think, to perform and to act with integrity; in dialogue with Silva, Almeida, Gatti (2016) and its references for teacher education: professional knowledge, professional practice and professional engagement. Methodologically, the CPP of the course was analyzed and eight new graduates were interviewed. The analysis considered: ithe strength / weakness of the disciplines; ii- the coexistence with teacher trainers and their practices; iii- the place that the teaching practices occupy. The findings suggest that the course

\footnotetext{
1 Mestre em Educação; Programa de Pós-graduação em Educação da UFRJ; Rio de Janeiro/BR; sabrynar@gmail.com.

${ }^{2}$ Doutora em Educação; Professora da Faculdade de Educação da UFRJ; Programa de Pós-graduação em Educação; Rio de Janeiro/BR; giselicruz@ufrj.br
}

Revista Devir Educação, Lavras, vol.4, n.1, p.47-76 jan./jun., 2020. 


\section{Q DEVIR EDUCAÇÃO \\ ISSN: 2526-849X}

favors the dimensions of the knowledge and of the teaching performance, only tangentiating the dimension of acting with integrity.

Keywords: Professional Teaching Culture; Teacher education; Pedagogy course.

\section{Resumen}

Este artículo se centra en la investigación con ocho graduados de un curso de Pedagogía sobre su visión acerca de las marcas de la cultura profesional en la formación docente. El objetivo del trabajo es analizar los elementos y / o contextos del curso que favorecen la aproximación entre los estudiantes y la profesión. El marco teórico se basa en Shulman (2005), en relación con las tres dimensiones de las marcas pedagógicas profesionales: pensar, ejercer y actuar con integridad; en diálogo Silva, Almeida, Gatti (2016) y sus referencias para la formación docente: conocimiento profesional, práctica profesional y compromiso profesional. Metodológicamente, se analizó el CPP del curso y se entrevistaron ocho nuevos graduados. El análisis consideró: ila fuerza / debilidad de las disciplinas; ii- la coexistencia con los formadores de docentes y sus prácticas; iii- el lugar que ocupan las prácticas de enseñanza. Los hallazgos sugieren que el curso favorece las dimensiones del conocimiento y del rendimiento docente, solo que tangenciona la dimensión de actuar con integridad.

Palabras clave: Cultura docente profesional; Educación docente; Curso de pedagogía.

\section{Introdução}

Na formação inicial universitária de professores, o contato que temos com a ideia da escola enquanto locus de manifestação do trabalho docente, no contexto dos estudos acadêmicos, e a possibilidade de vivência deste lugar através dos estágios e práticas de ensino nas escolas de Educação Básica, não são os únicos determinantes de nossa autoimagem enquanto profissional docente e, consequentemente, nossa postura frente à docência. Cabe, nesse caso, uma série de fatores, que partem desde a própria formação enquanto sujeito, às experiências ao longo da vida, o conjunto de valores e crenças que rodeia seu desenvolvimento, sua experiência escolar, entre outros - suas trajetórias pessoais e profissionais, que constroem, desconstroem e reconstroem a identidade profissional docente. Quais seriam então as marcas da cultura profissional docente construídas durante a formação inicial?

Shulman (2005), em artigo intitulado "Signature pedagogies of the professions", em tradução livre Assinaturas, ou marcas, pedagógicas das profissões, faz menção às características da cultura profissional que se manifestam, ou não, na formação de novos profissionais em cada curso de formação, no sentido de refletir sobre como se expressam os 


\section{Q DEVIR EDUCAÇÃO \\ ISSN: 2526-849X}

elementos que se relacionam com a aproximação ou o distanciamento da formação inicial com a cultura profissional. A partir de um paralelismo entre a noção de Erik Erikson (1987), de que uma boa forma de conhecer uma cultura é estudar seus berçários, pois ali irão se manifestar seus elementos estruturantes, e a ideia de que o mesmo ocorre com as profissões, sugere que para compreender a cultura de uma profissão, deve-se estudar seus berçários - os cursos de formação inicial. Para o autor, uma vez que se olhe para estes cursos, é possível identificar as formas características de ensino e aprendizagem, que chamou de marcas pedagógicas, perpassadas por três dimensões fundamentais: pensar, atuar, e agir com integridade.

Estas três dimensões enfatizadas nos cursos de formação profissional apontadas por Shulman (pensar, atuar, e agir com integridade) encontram-se com aquelas indicadas por Silva, Almeida, Gatti (2016) como referentes para a ação docente: o conhecimento profissional, a prática profissional e o engajamento profissional.

Se Shulman (2005) entende a dimensão do "pensar" como a mobilização dos saberes profissionais para o raciocínio adequado dentro daquela profissão, para Silva, Almeida, Gatti (2016), a dimensão do "conhecimento profissional" envolve os saberes relacionados ao campo profissional, quer sejam o saber proposicional (saber que) e o saber de caráter operativo (saber como $)^{3}$. Ambos, neste sentido, dizem respeito ao conjunto de conhecimentos necessários para a ação profissional. A segunda dimensão apontada por Shulman (2005), "atuar" (do inglês, perform), diz respeito à atuação profissional em seu locus de fato, à performance, ao desempenho propriamente dito na profissão. Aqui encontraria assento a dimensão da "prática profissional" enunciada por Silva, Almeida, Gatti (2016), que diria respeito também à atuação profissional em seu locus de fato. Já a terceira dimensão da formação profissional, que Shulman (2005) enuncia como "agir com integridade", Silva, Almeida, Gatti (2016) nomeiam como “engajamento profissional". Ambos dizem respeito aos princípios éticos e políticos que norteiam a prática profissional.

Tanto Shulman (2005) quanto Silva, Almeida, Gatti (2016) reconhecem que, embora sejam dimensões diferentes, a serem idealmente trabalhadas igualmente nos cursos de formação, estes tendem em geral a contemplar apenas uma ou outra, de modo que alguma destas dimensões frequentemente pode ficar de fora da concretização curricular dos cursos de

\footnotetext{
${ }^{3}$ O Saber proposicional, compreendido como o "saber que" (Know that) e o saber operacional, compreendido como o "saber como" (Know how) são distinções de saberes enunciadas por Gilbert Ryle (2002), e dizem respeito, respectivamente, às concepções e lógicas de organização do saber e às metodologias de ação.
}

Revista Devir Educação, Lavras, vol.4, n.1, p.47-76 jan./jun., 2020. 


\section{Q DEVIR EDUCAÇÃO \\ ISSN: 2526-849X}

formação profissional. Além disso, ambos reconhecem que a fragmentação das dimensões que contemplam conhecimento das que contemplam prática, constitui uma categorização didática para analisar os aspectos que norteiam a formação, mas que se interrelacionam de tal maneira que se tornam indissociáveis - e por este motivo, devem ser trabalhados de maneira adequada, sem que um destes seja negligenciado.

No ano de 2006, foram aprovadas pelo Ministério da Educação (MEC) as Diretrizes Curriculares para o Curso de Pedagogia, instituídas pela Resolução do Conselho Nacional de Educação, $n^{\circ}$. 01, de 15 de maio de 2006, e identificadas nos Pareceres CNE/CP nº. 5/2005 e $n^{\circ}$. 3/2006; e atualizadas na Resolução $n^{\circ}$. 02/2015. De acordo com esse ordenamento legal, o pedagogo deve ser preparado para trabalhar em diversas áreas nas quais sejam previstos conhecimentos pedagógicos; assim, a formação profissional deve contemplar não apenas a docência, mas gestão de sistemas, unidades e projetos educacionais, e diversas outras áreas da educação (hospitais, museus, centros culturais, recrutamento, seleção e treinamento de recursos humanos empresariais, etc). Mesmo dentro da docência, os cursos devem formar para atuação em duas etapas da Educação Básica (Educação Infantil e Anos iniciais do Ensino Fundamental) e as modalidades de ensino que lhe cabem (disciplinas pedagógicas do Curso Normal, Educação Escolar Indígena, Educação Especial, Educação de Jovens e Adultos, Educação do Campo e Educação Profissional). Além disso, também constituem área de atuação de pedagogos a administração, orientação e supervisão escolar, ainda que de forma subjacente.

A partir da compreensão de que o domínio do professor é a docência, e que esta se concretiza no processo de ensino-aprendizagem, surge a questão de como os cursos de formação docente estão formando os professores, dentro deste contexto de uma cultura profissional múltipla, que abrange formação para diferentes ênfases de trabalho

Nessa direção, desenvolvemos um estudo que teve por objetivo analisar as marcas da cultura profissional na formação de professores, a fim de buscar compreender de que maneira o curso de Pedagogia, enquanto formação inicial, favorece a aproximação entre o curso e a profissão docente e sua cultura profissional, na visão de recém-egressos. O foco do estudo residiu em investigar as marcas da cultura profissional docente desenvolvida no curso de Pedagogia de uma universidade pública, na visão de recém egressos. Buscamos analisar quais são os elementos de sua formação que permitiram ou propiciaram sua aproximação com a profissão docente e sua cultura profissional.

Revista Devir Educação, Lavras, vol.4, n.1, p.47-76 jan./jun., 2020. 


\section{OO DEVIR EDUCAÇÃO \\ ISSN: 2526-849X}

\section{Aspectos metodológicos}

Buscamos analisar quais são os elementos da formação de professores que permitiram ou propiciaram a aproximação com a profissão docente e sua cultura profissional através de entrevistas com egressos e análise documental do currículo do curso. Assim, o campo empírico foi constituído por egressos do curso de Pedagogia de uma Universidade federal localizada no Rio de Janeiro.

O Projeto Pedagógico de Curso (2007) da instituição indica uma compreensão sobre a preparação profissional pautada na sólida formação teórica e específica para a intervenção prática, tendo por pressuposto que a condição do professor constitui sua identidade básica, à qual se agrega a de profissional preparado para atuar nas diferentes esferas educacionais.

Ao integralizá-lo, o estudante passou por uma formação em cinco áreas específicas: Docência na Educação Infantil; Docência nos Anos Iniciais do Ensino Fundamental; Docência nas Disciplinas Pedagógicas do Curso Normal (modalidade do Ensino Médio); Docência na Educação de Jovens e Adultos; e Gestão de Processos Educacionais.

O currículo está organizado em três núcleos estruturantes, tal como definem as Diretrizes Curriculares Nacionais para o curso: I- Núcleo de estudos básicos, que compreende as disciplinas cujos saberes constituem o campo educacional e com ele dialogam; II- Núcleo de aprofundamento e diversificação de estudos, cujas disciplinas abrangem a docência e os campos a ela relacionados, bem como aprofundamento nas modalidades de ensino da Pedagogia; e IIINúcleo de estudos integradores, que abarca as atividades acadêmicas complementares e todas as possibilidades acadêmicas oferecidas. A partir da Resolução $n^{\circ}$. 02/2015 houve atualização da estruturação destes núcleos:

I - núcleo de estudos de formação geral, das áreas específicas e interdisciplinares, e do campo educacional, seus fundamentos e metodologias, e das diversas realidades educacionais (...); II - núcleo de aprofundamento e diversificação de estudos das áreas de atuação profissional, incluindo os conteúdos específicos e pedagógicos, priorizadas pelo projeto pedagógico das instituições, em sintonia com os sistemas de ensino (...); III - núcleo de estudos integradores para enriquecimento curricular. (BRASIL, 2015b)

Revista Devir Educação, Lavras, vol.4, n.1, p.47-76 jan./jun., 2020. 


\section{Q DEVIR EDUCAÇÃO \\ ISSN: 2526-849X}

A Resolução $n^{\circ}$ 02/2015 também estabelece quee todos os cursos de formação de professores têm prazo até o mês de dezembro de 2019 para adequar os PPC a esta resolução. O PPC do curso estudado nesta pesquisa foi elaborado no ano de 2007 e passou por atualização no ano de 2015 a fim de atender às demandas da Resolução $n^{\circ}$ 02/2015. Comparativamente, os três novos núcleos que virão a estruturar o currículo dos cursos de Pedagogia a partir da nova resolução estão de acordo com os três núcleos que já em 2007 estruturavam seu curso de Pedagogia, porém expandindo e ou ampliando seu conteúdo. Os três núcleos envolvem atividades acadêmicas obrigatórias e optativas, abrangendo disciplinas, estágios, extensão e monografia. Assim, a duração do curso totaliza 3.435 horas, distribuídas nas atividades relacionadas ao longo de 9 ou 10 períodos acadêmicos, de acordo com o turno de escolha - o curso noturno possui um período a mais.

O curso possui cinco componentes obrigatórios de Estágio Curricular Supervisionado com suas respectivas Práticas de Ensino. Cada uma destas corresponde a uma área específica do curso e possui 160h de carga horária, sendo 100 horas de Estágio Supervisionado, realizado em uma escola ou instituição parceira, sob a supervisão do professor da escola e acompanhamento do professor da Universidade; e 60h de Prática de Ensino, realizadas na Universidade, sob orientação do professor da disciplina.

No último período acadêmico, os alunos realizam a Orientação em Monografia, onde, sob orientação de um docente, desenvolvem individualmente um trabalho monográfico de conclusão de curso, a ser defendido em banca composta por professores da instituição. Havendo cumprido todos os requisitos, é possível então realizar a colação de grau.

A não-obrigatoriedade de participação em projetos e programas acadêmicos ou mesmo contextos de outra ordem, como movimentos estudantis, torna o perfil do egresso do curso de pedagogia bastante diverso. O currículo não se orienta por um sistema de pré-requisitos. Assim, apesar de ter uma ordenação recomendada, muitos alunos optam por desenhar suas próprias grades horárias, redistribuindo a ordem e quantidade de disciplinas cursadas. Por vezes, isso acontece por demandas pessoais e profissionais, já que muitos estudantes trabalham e/ou realizam estágios não-obrigatórios. Muitas vezes, porém, a liberdade de organização das próprias grades horárias favorece um desenho voltado para a participação dos diferentes contextos acadêmicos oferecidos pela Universidade e que, dada a sua natureza e função, interessaram mais ao estudo realizado.

Revista Devir Educação, Lavras, vol.4, n.1, p.47-76 jan./jun., 2020. 


\section{Q DEVIR EDUCAÇÃO \\ ISSN: 2526-849X}

Como a estrutura do curso favorece o desenho de diferentes trajetórias, seus egressos podem trazer diferentes marcas, de acordo com os contextos acadêmicos frequentados. Assim, no sentido de estudar as marcas pedagógicas do curso, e então identificar marcas da cultura profissional docente nos sujeitos investigados, faz-se necessário garantir que estas possibilidades acadêmicas sejam contempladas em suas trajetórias na seleção destes sujeitos.

Nesse cenário, foram procurados sujeitos com graduação finalizada entre os anos de 2013 e 2016 e ao menos parte deles em processo de inserção profissional. Isso porque como o objetivo residiu em olhar para o curso de formação inicial, procurou-se evitar quem já tivesse atuação profissional tal que, por tempo de imersão no campo da profissão, estivesse impregnando-se das marcas da experiência. Por este mesmo motivo, foram determinados como critérios de seleção, além do período de colação de grau, sujeitos que tenham tido no curso de Pedagogia investigado sua formação inicial docente, sem que tenham realizado qualquer tipo de formação anterior (curso Normal, Normal Superior ou Licenciatura), ou estágios remunerados na educação básica ao longo da graduação.

O quadro de sujeitos foi montado a partir dos critérios mencionados, de modo que, considerando as possibilidades de formação em um contexto universitário, com ensino, pesquisa e extensão, pelo menos um dos sujeitos tenha participado de uma dessas atividades, indo além do percurso obrigatório do curso, e pelo menos dois desses sujeitos tenham frequentado apenas o mínimo requisitado pela matriz curricular para colação de grau, restringindo a experiência na graduação aos requisitos obrigatórios do curso. Assim, buscou-se os sujeitos a partir dos contextos, nominalmente: Programa de Monitoria ${ }^{4}$, de Extensão ${ }^{5}$,

\footnotetext{
${ }^{4}$ Programa de Monitoria: programa de complementação da formação, que visa despertar o interesse pela docência, através da co-participação das atividades de ensino-aprendizagem realizadas no contexto da disciplina em que está inserido.

${ }^{5}$ Programa Extensão: programa que visa aproximar a Universidade das comunidades, através da participação em cursos e projetos que envolvam essas duas instâncias, no caso do curso em questão, relacionados à educação.
}

Revista Devir Educação, Lavras, vol.4, n.1, p.47-76 jan./jun., 2020. 
Movimentos Estudantis ${ }^{6}$, Programa de Iniciação Científica $\left(\right.$ PIBIC) ${ }^{7}$ e Programa de Iniciação à Docência (PIBID) ${ }^{8}$. Trata-se, assim, de uma seleção intencional e particular.

O quadro 1 registra o grupo de sujeitos, constituído por 8 (oito) egressos, sendo apenas um do sexo masculino, e todos os demais do sexo feminino. Todos realizaram a colação de grau entre os anos de 2013 e 2016, e suas idades compreendem a faixa etária de 23 a 50 anos, tendo maior prevalência sujeitos entre os 23 e 26 anos. Destes, quatro encontram-se inseridos na profissão docente, realizando a inserção profissional em rede pública de ensino.

Quadro 1 - Quadro de sujeitos - Local - ano.

\begin{tabular}{cccccc}
\hline $\begin{array}{c}\text { Identificação } \\
\text { do sujeito }\end{array}$ & Sexo & Idade & $\begin{array}{c}\text { Ano de } \\
\text { colação }\end{array}$ & $\begin{array}{c}\text { Contextos } \\
\text { frequentados }\end{array}$ & $\begin{array}{c}\text { Trabalha com } \\
\text { docência }\end{array}$ \\
\hline AM & F & 31 & 2014 & - & Não \\
CN & F & 50 & 2013 & Extensão & Sim \\
DZ & F & 27 & 2015 & CxA & Não \\
EP & M & 25 & 2015 & Iniciaçããa Científica & Sim \\
FL & F & 25 & 2015 & CA & PIBID EF \\
JF & F & 25 & 2015 & PIBIC & Sim \\
\hline
\end{tabular}

\footnotetext{
${ }^{6}$ Movimentos Estudantis: a participação em movimentos sociais estudantis favorece a formação da dimensão política e a prática da democracia. O curso possui um Centro Acadêmico, que realiza atividades e eventos de formação educacional, política e de engajamento social, e exerce a representatividade discente em diversos espaços acadêmicos.

${ }^{7}$ Programa Institucional de Bolsa de Iniciação Científica: programa com inserção em grupos de pesquisa, a fim de proporcionar experiências em pesquisa acadêmica.

${ }^{8}$ PIBID - Programa Institucional de Bolsas de Iniciação à Docência: programa de iniciação a docência, que articula inserção em contexto escolar, em escolas públicas, com acompanhamento do professor supervisor na escola, e de um professor especialista na Universidade, a fim de proporcionar ao licenciando experiências de ensino-aprendizagem da docência, tanto na Educação Infantil (PIBID EI) quanto no Ensino Fundamental (PIBID EF), concedendo bolsas não só aos estudantes, mas também aos professores supervisores da educação básica e da Universidade.

${ }^{9}$ Para preservar o anonimato dos sujeitos, adotou-se a sua identificação por meio de duas letras alfabéticas.
} 


\section{QO DEVIR EDUCAÇÃO \\ ISSN: 2526-849X}

\begin{tabular}{lccccc}
\hline MS & F & 26 & 2016 & $\begin{array}{c}\text { Extensão } \\
\text { Monitoria }\end{array}$ & Não \\
VM & F & 35 & 2016 & - & Siciação Científica \\
\hline
\end{tabular}

Fonte: Do autor (2017).

Para obter dos sujeitos sua visão acerca das marcas da cultura profissional docentes no seio do curso de Pedagogia, recorremos à entrevista. Desse modo, as narrativas dos sujeitos, resgatando informações a partir de sua memória, constituem os dados desta pesquisa. Ora, a memória não necessariamente é limitada à narração fiel de dados factuais, tais quais ocorreram, e sim pode incluir uma série de fatores subjetivos, relacionados à experiência e à identidade do sujeito; pode, muitas vezes, nos trair, sendo seletiva e ressignificada a partir de sentimentos e de interpretações. Assim, é necessário o cuidado em buscar compreender e situar as memórias dos sujeitos, sabendo-as imbuídas de uma série de processos que possam ressignificar as experiências. Para tanto, a análise foi desenvolvida a partir de um processo meticuloso de leitura, releitura e arrumação das falas.

Das entrevistas realizadas e transcritas, foi realizada inicialmente a leitura de cada uma delas por três vezes; a primeira leitura, para tomar ciência do contexto; a segunda, conferindo com o áudio, para garantir a fidedignidade da informação; e a terceira vez, em um processo de organização primária dos dados. A partir de então, as falas foram inúmeras vezes visitadas, a fim de compor a sistematização dos dados.

Para que fosse favorecido esse processo de analisar as falas a partir das memórias dos depoentes, foram organizados vários quadros descritivos. Para cada pergunta da entrevista, foi elaborado um quadro, contendo campos com os nomes dos sujeitos da pesquisa, e suas respectivas falas.

Em relação às perguntas que exigiram maior elaboração, na arrumação das respostas dentro do campo de cada sujeito, foram incluídas todas as considerações do mesmo sobre aquela questão, ao longo de toda a entrevista, não limitando-se apenas às respostas dadas no momento da pergunta.

Após a montagem de cada quadro, foram listados os elementos recorrentes, as aproximações, assim como as dissonâncias e possíveis contradições. Num último movimento, 


\section{QO DEVIR EDUCAÇÃO \\ ISSN: 2526-849X}

foram destacados das falas dos sujeitos aquilo que fosse referente a cada contexto transitado, a fim de observar se, dentre os que falaram sobre, houve consonâncias e dissonâncias.

Tal arrumação permitiu a identificação das evidências e relevos, das convergências e divergências, aproximações e afastamentos. Algumas questões foram extensamente comentadas, como o fato de predominar, na estrutura curricular do curso, as disciplinas como locus de formação; e também o lugar das práticas de ensino, que aparecem quase como uma unanimidade entre os sujeitos. Há divergências, porém, no que tange às experiências individuais, que variam com a especificidade de cada prática, a escola alocada, e as práticas e a convivência, tanto com os professores da Universidade que supervisionam as práticas, quanto com os professores regentes que acolhem os estudantes na escola - fatores que parecem influenciar diretamente na formação desses sujeitos e em suas impressões sobre a docência.

A análise dos dados permitiu depreender assim três eixos de discussão: i- a força/fraqueza das disciplinas; ii- a convivência com professores formadores e suas práticas; e iii- o lugar das práticas de ensino.

\section{A força/fraqueza das disciplinas}

Pesquisas recentes sobre os cursos de formação de professores vêm demonstrando que as disciplinas ocupam a maior parte dos currículos. Gatti (2010) traz, após analisar currículos de 71 cursos presenciais de Pedagogia, em nível superior, nas cinco regiões do país, de instituições públicas e privadas, que apenas 5,9\% correspondem a "Atividades Complementares", que ao lado de Pesquisa e Trabalho de Conclusão de Curso (7,0\%), correspondem a apenas $12,9 \%$ do currículo. Os demais $87,1 \%$ são dedicados a disciplinas, divididas pela autora nas seguintes categorias: Fundamentos teóricos da educação; Conhecimentos relativos aos sistemas educacionais; Conhecimentos relativos à formação profissional específica; Conhecimentos relativos às modalidades e nível de ensino; e Outros saberes.

A natureza predominantemente disciplinar dos cursos de Pedagogia lega às disciplinas uma força formativa passível de deixar marcas significativas na formação docente. De fato, todos os sujeitos entrevistados trouxeram à tona alguma questão relacionada às disciplinas

Revista Devir Educação, Lavras, vol.4, n.1, p.47-76 jan./jun., 2020. 


\section{Q DEVIR EDUCAÇÃO \\ ISSN: 2526-849X}

cursadas. Há o reconhecimento da importância dos conhecimentos nelas apresentados para aprendizagem e exercício da docência, porém mais forte ainda é a impressão de que apenas as disciplinas, referenciadas como excessivamente teóricas, não foram suficientes para preparar para a inserção profissional:

As primeiras disciplinas do curso, as de fundamentos, foram me contextualizando sobre o cenário da Educação Brasileira, e me inserindo um pouco no curso. Ainda não tinha essa ideia de docência, porque não tinha nenhuma disciplina falando sobre isso. (FL)

A fala exposta exemplifica também outra recorrência: a distância entre as disciplinas e o contexto de atuação, no início do curso, que tem em seus primeiros períodos acadêmicos uma matriz curricular voltada para as disciplinas de Fundamentos da Educação. No caso do curso em questão, trata-se de conhecimentos que Gauthier (1998) chama de "saberes das ciências da educação", e que abrangem disciplinas como Filosofia da Educação, Sociologia da Educação, Antropologia da Educação, História da Educação, Psicologia da Educação, entre outros.

Na classificação da base de conhecimento profissional docente de Shulman (2004), tais conhecimentos alojam-se no que ele chama de conhecimento das finalidades, as propostas e valores educacionais, onde encontram-se os saberes de outras áreas que, juntas, ajudam a traçar o panorama educacional, e que tratam também daquilo que Silva, Almeida, Gatti (2016) chama de saber proposicional - o saber que - dentro do conhecimento profissional. A preocupação de Shulman (2004), no contexto da base de conhecimento que inclui tais saberes, está em classificá-la e em desenvolver meios de acessá-la e mobilizá-la no processo de raciocínio e ação pedagógica. Nisto consistiria então a aprendizagem da docência. Embora estes saberes constituam a base e tenham seu lugar para o autor, assim como saberes de outras ordens, a ênfase está em olhar para uma formação sólida no conteúdo a ser ensinado, que ele chama de conhecimento do conteúdo; no conhecimento dos processos pedagógicos, que envolvem os saberes da pedagogia; e no conhecimento pedagógico do conteúdo: um amálgama entre conteúdo e pedagogia que seria então o domínio específico do professor. Atentando para a importância de tais saberes, entretanto, Shulman (2004) não aponta qual seria o momento formativo mais adequado, na aprendizagem inicial da docência, para alocar cada um deles; enfatiza, porém, que a base de conhecimento está no cerne de uma das dimensões da formação

Revista Devir Educação, Lavras, vol.4, n.1, p.47-76 jan./jun., 2020. 


\section{Q DEVIR EDUCAÇÃO \\ ISSN: 2526-849X}

profissional: o pensar, que diz respeito aos saberes que constituem a base, e à forma correta de mobilizá-los no raciocínio adequado dentro da profissão.

O formato em que o currículo do curso se apresenta, de acordo com o apontado pelos estudantes, no qual as disciplinas iniciais fundamentam o amálgama de conhecimentos de outros campos para delinear o campo educacional, completamente afastado do contex to escolar, parece estar em consonância com a impressão de afastamento da realidade profissional mencionada na introdução deste trabalho, quando comentada a ausência de rito ou de elementos que ajudem o estudante a desenvolver a sensação de pertencimento à classe profissional no curso em questão.

De acordo com Gatti (2010), o ciclo básico dos cursos de Pedagogia tende a ser formado inicialmente por essas disciplinas de fundamentos, seguindo à medida em que o curso avança para disciplinas que envolvem outros tipos de saberes, desde aqueles relativos aos sistemas educacionais, à formação específica profissional e às modalidades e níveis de ensino, além de saberes de outra natureza.

No caso específico do curso de Pedagogia investigado, este está organizado em três núcleos estruturantes: Núcleo de estudos básicos; Núcleo de aprofundamento e diversificação de estudos; e Núcleo de estudos integradores. Enquanto os dois primeiros dizem respeito às disciplinas, o terceiro núcleo, de estudos integradores, envolve as atividades acadêmicas complementares.

Verifica-se, assim, que o próprio Projeto Pedagógico de Curso prevê a importância e necessidade de atividades que fujam do conjunto de disciplinas. O currículo está estruturado de tal maneira a abranger, na matriz obrigatória, horas de atividades que incluem disciplinas de livre escolha e atividades de extensão. A duração recomendada para a integralização do curso é de 9 períodos para o diurno, e 10 períodos para o noturno, estruturados de tal maneira que cada período possua carga horária distribuída entre cinco disciplinas e, em alguns destes períodos, atividades acadêmicas optativas de escolha condicionada e de grupo de extensão.

Ora, o curso é oferecido nos três turnos (matutino, vespertino e noturno), de modo que os alunos se matriculam em um turno específico. Há a possibilidade de cursar disciplinas em turnos diferentes daquele de origem. No entanto, com a inclusão de cinco disciplinas por período, sendo cada uma oferecida em um dia da semana; e a semana letiva compreendendo os dias úteis (segunda-feira a sexta-feira), o aluno que deseja seguir a duração recomendada precisa dispor de tempo além de seu turno, o que nem sempre é possível. Tal problema se agrava

Revista Devir Educação, Lavras, vol.4, n.1, p.47-76 jan./jun., 2020. 


\section{QO DEVIR EDUCAÇÃO \\ ISSN: 2526-849X}

quando se trata das práticas de ensino, que totalizam cinco componentes curriculares, e incluem o momento da disciplina em sala de aula, e o momento de imersão em campo - que também devem ocorrer em um momento além daquele do turno do aluno. Assim, não raro, os estudantes fragmentam suas grades curriculares, extrapolando o tempo recomendado de integralização do curso. Se a própria estrutura curricular mínima disposta, cujo curso não se coloca como integral, mas que, pela disposição da estrutura curricular recomendada, sugere a realização de atividades fora de seu turno, o aluno que, por motivos alheios - frequentemente, devido à necessidade de trabalhar paralelamente à graduação - não disponha de tempo fora de seu turno de origem, fica prejudicado em relação às possibilidades de transitar por outros contextos da Universidade:

Trabalhei durante a graduação em loja de shopping porque o shopping era perto da faculdade e porque pagava muito melhor que escola. Um estágio em escola paga 300, 400 reais e você trabalha correndo atrás de criança, trocando fralda, e na loja eu tirava um mínimo e mais comissão, além dos beneficios, então era 1.500 por mês, mais a passagem, e eu não podia largar. Trabalhava de dez às cinco, só tinha tempo de me trocar e comer alguma coisa no shopping mesmo e ir para a aula. Como é que eu ia arrumar tempo para fazer pesquisa? Extensão? PIBID? Impossível! Já tive que tirar férias no trabalho para poder fazer os estágios obrigatórios... (AM)

Não trabalhei ao longo da graduação, então tive tempo de participar de muitas coisas. Se tivesse trabalhado, não teria tido tempo de participar do Centro Acadêmico, e principalmente da pesquisa, porque praticamente todas as reuniões de grupos de pesquisa são de tarde, e eu era do turno da tarde. Tive que puxar disciplinas da manhã e da noite para poder liberar as tardes das pesquisas. (DZ)

Neste caso, a entrevistada AM representa um grupo de estudantes que não teve a chance de participar de outros contextos acadêmicos, devido à necessidade de trabalhar ao longo do curso de pedagogia. Já DZ faz parte do grupo que, pela ausência de tal necessidade, dispôs de tempo para participar de outras atividades, como o Centro Acadêmico e grupos de Pesquisa. Esses dois extremos são frutos do efeito da estrutura do curso. Ora, um curso que se organiza de tal maneira que a matriz curricular inclua 45 disciplinas obrigatórias, e um quadro de 50 disciplinas complementares disponíveis dentre as quais os alunos podem escolher aquelas que cursarão (observando o mínimo de 9 créditos obrigatórios) de modo que, quando da graduação, tenham cursado uma carga horária mínima de 3.435 horas, tem nas disciplinas uma força formativa descomunal.

Revista Devir Educação, Lavras, vol.4, n.1, p.47-76 jan./jun., 2020. 


\section{Q DEVIR EDUCAÇÃO \\ ISSN: 2526-849X}

Essa força, no entanto, transforma-se em fraqueza, quando a estrutura curricular prevista, embora flexível quanto à inexistência de pré-requisitos disciplinares, dificulta as possibilidades de acesso de estudantes ao contato com outros contextos acadêmicos, que favoreceriam a aproximação entre os estudantes e a cultura profissional, visto que, de acordo com as falas trazidas das entrevistas, e conforme afirma Gatti (2010), da maneira como são estabelecidas, tais disciplinas aparentam ser insuficientes para a formação docente.

Ora, afirmar que a privação da oportunidade de transitar por contextos acadêmicos diferenciados constitui uma fraqueza dentro de um currículo que tem sua força justamente em sua natureza disciplinar, pode parecer contraditório. No entanto, os próprios sujeitos entrevistados fazem menção à importância de tal movimento exterior às disciplinas, em sua formação docente:

A pesquisa, acho que me ajudou a criar uma atitude de problematização e reflexão, e me ajudou a estudar. A gente acha que sabe estudar, mas no fim das contas meio que não sabe. A pesquisa me ensinou a buscar e selecionar informações, a elaborar conhecimento. Então me ajuda a organizar, sistematizar e compreender meu próprio conhecimento sobre a docência. (DZ)

Todo o meu movimento na graduação foi importante. Mas posso dizer com certeza que a Extensão teve um papel fundamental no meu "ser professora". $(\mathrm{CN})$

Fiquei muito tempo no PIBID, então estou muito marcada pelo PIBID. Então não sei nem como seria se fosse diferente, sabe? Por isso foi muito bom, minha formação foi construida junto com o PIBID. (FL)

Da mesma maneira, os sujeitos apontaram o não ter passado por determinados contextos, como fragilidade em sua formação:

Sinto falta de ter vivido mais a Universidade. Das pesquisas, etc. (MS)

Eu queria ter tido experiências mais voltadas para a sala de aula mesmo, como o PIBID. Acho que seria uma profissional melhor. Mas foram poucas e isso não foi suficiente quando entrei em sala de aula pela primeira vez. (VM)

Revista Devir Educação, Lavras, vol.4, n.1, p.47-76 jan./jun., 2020. 


\section{Q DEVIR EDUCAÇÃO \\ ISSN: 2526-849X}

As próprias Diretrizes Curriculares Nacionais para o curso de Pedagogia, reconhecem a importância e necessidade de participação em âmbitos como a iniciação científica, extensão e monitoria - ainda que, em termos de carga horária, o espaço mínimo a ser dedicado para isto nos cursos não chegue a 3,2\% do curso, em contrapartida às disciplinas, que ocupam $87,5 \%$. Assim, observa-se que não se trata de uma questão do curso em si, mas de uma questão da sua proposta de formação inicial docente.

Com as Diretrizes Curriculares estipulando um percentual tão alto da carga horária do curso voltada para as disciplinas, reservando apenas $9.3 \%$ da carga horária para os estágios e práticas de ensino em locus de atuação profissional (escolas e demais instituições educacionais), e uma carga horária muito reduzida de atividades profissionais, pode-se entender que a ênfase no pensar, conforme entendido por Shulman (2005), enquanto processo de raciocínio necessário para exercer as atividades inerentes à profissão, constitui uma marca pedagógica dos cursos de Pedagogia, sendo assim forte elemento constituinte da cultura profissional docente.

\section{A convivência com professores formadores e suas práticas}

Cochran-Smith (2012) afirma que a aprendizagem da docência é algo que não ocorre pontualmente. Apesar de existir um marco temporal de início de tal trajetória, esta não se esgota a ponto de, findo um curso inicial de formação, o sujeito já estar perfeitamente pronto e apto a exercer a docência da maneira mais eficiente possível. Do contrário, para a autora, a aprendizagem ocorre ao longo da vida profissional, e depende diretamente do contato entre professores novatos, e aqueles mais experientes.

Ao longo das entrevistas, embora o foco fosse inicialmente olhar para a contribuição dos âmbitos acadêmicos que os sujeitos percorreram para sua formação docente, esta questão se destacou, sendo recorrente em suas falas a importância de seus professores formadores, em relação às próprias práticas docentes:

Acho que os professores influenciam muito nessa questão de você se sentir alguém consciente da docência ou não, com a sua própria prática. (DZ)

Revista Devir Educação, Lavras, vol.4, n.1, p.47-76 jan./jun., 2020. 


\title{
Q DEVIR EDUCAÇÃO \\ ISSN: 2526-849X
}

Meio que me espelhei em alguns dos professores que conheci na faculdade. $\mathrm{E}$ acabei interiorizando minha visão do ser docente com a imagem destes professores. (EP)

Não apenas o contato com os professores da Universidade foi citado com frequência. Os sujeitos também trouxeram os professores regentes de escolas que os receberam nos estágios, como importantes no processo de aprendizagem da docência:

\begin{abstract}
Entre os estágios, o de séries iniciais, porque era no Colégio $\mathrm{Z}$ e porque a professora da turma sempre tirava um tempo depois da aula para explicar as coisas. Ela explicava as atividades do dia, intervenções que fazia com as crianças, falava sobre elas. Então era como se a aula que a gente assistia ela dar, fosse uma aula pra gente de como ser professora. Tipo como se a gente vivesse o "exemplo", a situação, e depois ela explicava: "isso aconteceu por causa disso. Nessa hora o menino disse tal coisa, eu agi assim por isso". Ela mesmo reconhecia às vezes, "agi assim mas acho que seria melhor ter agido assim". Isso ajudava a gente a entender que por mais que parecessem reações reativas as da professora, elas não eram sem sentido, não era instinto, ela agia pedagogicamente. E explicava pra gente. Então acho que se tiver que pensar em algo da faculdade que às vezes lembro e que me ajuda, são algumas situações que vivi no Colégio Z. (VM)
\end{abstract}

Assim, embora afirmem a carência do contato com a escola enquanto âmbito de atuação, os sujeitos destacam o movimento de perceber seus próprios professores como exemplos de prática docente, tanto pelos exemplos positivos, quanto no sentido de práticas com as quais não concordam:

Quando um calouro chega, a gente já diz logo quais professores não pegar. Tem muito professor ruim, que enrola. Tem professor que falta muito, ou que inventa seminários e trabalhos em grupo para não dar aula. Tem professor rígido e incompreensivo. Tem professor incoerente, que prega uma perspectiva, mas que age em outra completamente diferente. Tem uns que são até caricatos na Faculdade. Fugi ao máximo desses professores, porque como não tive tempo de investir direito na minha formação por causa do trabalho, meu tempo na faculdade eu queria aprender. Mas nem sempre dava e tinha que fazer com eles. E esses professores acabam, em conjunto, resumindo e personificando a professora que eu não quero ser. (AM)

Revista Devir Educação, Lavras, vol.4, n.1, p.47-76 jan./jun., 2020. 


\section{OO DEVIR EDUCAÇÃO \\ ISSN: 2526-849X}

Fica evidente, assim, que as práticas dos professores mais experientes, seja no âmbito da Universidade ou nas práticas de ensino na escola, impactaram diretamente na visão e na relação dos sujeitos com e sobre a docência.

Como já exposto, Shulman (2005) afirma que os cursos de formação profissional usualmente enfatizam duas das três dimensões da aprendizagem profissional (pensar, atuar $e$ agir com integridade), frequentemente negligenciando uma delas. Ao trazerem exemplos recorrentes de professores cuja preocupação em sala-de-aula voltava-se para o ensino do conteúdo disciplinar, por vezes ignorando serem suas próprias práticas promotoras de aprendizagem da docência, os sujeitos fazem aparecer uma característica que faz pensar, dentro desta perspectiva das marcas pedagógicas, na possibilidade de ser o agir com integridade uma dimensão negligenciada no curso. O agir com integridade diz respeito à postura dos profissionais, aos princípios éticos e políticos que norteiam sua prática profissional, e que Silva, Almeida, Gatti (2016) nomeiam como “engajamento profissional”, e assim definem:

O sentido do engajamento, no que concerne à ação do professor, traduz-se nas maneiras pelas quais demonstra, em seu ambiente de trabalho, espírito de cooperação e de parceria, com consciência das responsabilidades individuais e coletivas da escola para com a aprendizagem e o desenvolvimento humano dos alunos. Compreende o sentido ético e social de sua ação. Procura desenvolver-se profissionalmente, de diferentes modos, em busca da contínua melhoria de seu trabalho e de seus pares. Contextualiza seu trabalho e considera a comunidade, suas condições e contribuições. (SILVA, ALMEIDA, GATTI, 2016, p.309).

Apesar de tal enunciação tratar da perspectiva do professor no contexto escolar, quando olhamos para professores de curso de formação docente, esta dimensão trata também da compreensão do professor acerca de suas responsabilidades e do próprio sentido da profissão.

Embora não enxergue a formação acadêmica como um conhecimento docente propriamente dito, constituinte da base de conhecimento profissional docente, e sim como uma fonte do conhecimento dos conteúdos disciplinares, conforme discutido no capítulo anterior, Shulman (2004) entende que este momento formativo não é suficiente para preparar um estudante para a docência:

Revista Devir Educação, Lavras, vol.4, n.1, p.47-76 jan./jun., 2020. 


\section{OO DEVIR EDUCAÇÃO \\ ISSN: 2526-849X}

Enquanto uma base de conhecimento acadêmico seja necessária para o trabalho profissional, está longe de ser suficiente. Assim, membros das profissões devem desenvolver a capacidade de aprender com experiência e com a contemplação da própria prática. Lições práticas aprendidas da experiência devem encontrar uma maneira de chegar à comunidade de praticantes, para que todos possam se beneficiar das experiências uns dos outros. As lições de prática devem também encontrar o caminho até a Academia para informar, assim como problematizar, o desenvolvimento do conhecimento da própria Academia. (SHULMAN, 2004, p. 535).

Ele reconhece então o lugar da experiência na constituição do próprio conhecimento disseminado na academia. Ora, se para o autor, a universidade deve se reconfigurar a partir da problematização da experiência advinda da prática, e se o momento de aprendizagem de conteúdos disciplinares é enxergado pelos estudantes como um momento de aprendizagem da atuação docente, a postura investigativa deve estar presente não apenas no contexto escolar, mas também no contexto do ensino da docência, por parte do professor formador. Isso porque, ao conviver com os professores na universidade, ao longo da graduação, apesar de serem constantemente colocados, e consequentemente se colocarem no papel de discentes, conforme suas falas, os estudantes reconhecem ser o próprio momento formativo, no contexto das aulas das disciplinas que frequentam, um momento de observação da docência, a partir da atuação de seus professores e, portanto, um momento de observação da prática docente, de modo que o que está sendo aprendido não trata apenas do conteúdo da disciplina ensinada, como sugere Shulman (2004), mas a própria docência. Nesta perspectiva, muito mais do que o contato com o conhecimento disciplinar, todo o curso que, como já visto, é estruturado de maneira predominantemente disciplinar, favorece o contato dos estudantes com a profissão.

\section{O lugar das práticas de ensino}

As Diretrizes Curriculares Nacionais para o curso de Pedagogia (Resolução n. 02/2015, art. 13. Inciso II) determinam o mínimo de 400 horas no currículo a serem dedicadas ao estágio supervisionado, amplicando a carga horária que, até então, deveria somar 300 horas mínimas a esta atividade, o que então correspondia a aproximadamente $9,4 \%$ da carga horária total. No

Revista Devir Educação, Lavras, vol.4, n.1, p.47-76 jan./jun., 2020. 


\section{Q DEVIR EDUCAÇÃO \\ ISSN: 2526-849X}

caso do contexto investigado, no entanto, a quantidade de horas destacadas para a realização das práticas de ensino já superava o tempo mínimo solicitado, totalizando 500 horas de estágio e 300 horas de prática de ensino correspondendo à supervisão do estágio.

A preocupação em determinar uma carga horária que constitui quase o triplo da recomendada pelas DCN demonstra o cuidado que o currículo do curso lega à dimensão que Shulman (2005) denomina o atuar, que diz respeito, como já dito, à prática profissional propriamente dita em seu locus de fato. Sobre essa dimensão, que Silva, Almeida, Gatti (2016) chamam de prática profissional, os autores colocam:

A prática profissional compreende os aspectos envolvidos na criação de condições de aprendizagem pelo compromisso com o desenvolvimento de todos os alunos em sua diversidade. Essa dimensão envolve as habilidades de planejar e promover situações de ensino que favoreçam a problematização, as indagações, a curiosidade e a investigação, momentos em que os alunos reelaboram as relações com os conteúdos de aprendizagem. Considera os conhecimentos prévios dos estudantes e diferentes formas de interação e socialização. Compõem essa dimensão a promoção de um clima favorável às relações de confiança e respeito, o uso de procedimentos variados e adequados aos objetivos e conteúdos de ensino, bem como o acompanhamento permanente das aprendizagens com a finalidade de promover apoio aos alunos, considerando seus diferenciais, além do aperfeiçoamento da prática educativa. (SILVA, ALMEIDA, GATTI, 2016, p.308)

São esses os aspectos que as práticas de ensino se propõem a deixar conhecer pelos estudantes, no âmbito de atuação profissional, a partir da prática docente dos professores regentes que os recebem. O lugar da prática de ensino aparece então como o momento de contato com a realidade escolar. De fato, comentam os sujeitos:

Acho que o que mais me aproximou da profissão docente, além dos professores, foram os estágios, particularmente o estágio em uma escola especial de jovens e adultos. (EP)

Os estágios obrigatórios. Porque a gente tinha contato com o cotidiano, a realidade da sala de aula, com a escola, instituição, com a profissão e o cotidiano escolar. Sai da ficção, da teoria, da historinha, e tem acesso à vida real. (MS)

Revista Devir Educação, Lavras, vol.4, n.1, p.47-76 jan./jun., 2020. 


\section{Q DEVIR EDUCAÇÃO \\ ISSN: 2526-849X}

Assim, dentro de um currículo que, conforme já comentado, se orienta principalmente pelo conhecimento disciplinar, as práticas de ensino oferecem o contato com a atuação docente. De acordo com os sujeitos participantes deste estudo, o tempo destinado às práticas - embora maior do que o recomendado pelas Diretrizes Curriculares Nacionais - é bastante curto (um período acadêmico), permeado de percalços e burocracias que o diminuem ainda mais. Entre essas burocracias citadas estão os movimentos relacionados ao trâmite de documentações exigidas, incluindo as autorizações para entrada em campo. Além disso, surgem greves e outras situações que prejudicam o aproveitamento do tempo e, consequentemente, a imersão na escola.

Os estágios. Mas dura muito pouco! Até o semestre começar, providenciarmos a documentação, a professora assinar, levar na escola, pegar o aceite de vaga, levar na CRE, ainda tem que conseguir atendimento na CRE, depois e voltar na escola, pra acertar detalhes... Quando isso acontece, a gente já perdeu pelo menos um mês nessa brincadeira, sobram o que, 2 ou 3 meses? Pra aprender como ser professor? É pouco demais. (AM)

A coisa não é como deveria ser. É, porque assim. O tempo do estágio é muito curto. E a gente meio que só observa na maior parte deles. Alguns como a Educação Infantil, a Professora $\mathrm{Y}$ até estimulava a gente a participar e na escola que fiz, a gente colocava a mão na massa, mas ajudando, auxiliando, não aprendendo. (VM)

Os trechos acima também apontam outra questão recorrente nas falas dos depoentes: embora reconheçam o momento do estágio como um importante contato com a realidade escolar, os entrevistados também apontam, conforme enuncia VM acima, que os estágios não acontecem sempre da maneira como deveriam ser, ou seja, como preconizado pelo PPC, proporcionando experiências diversas na prática docente propriamente dita, a partir de, entre outras, atividades de coparticipação. Do contrário, de acordo com seus depoimentos, as atividades desempenhadas, quando presentes, nem sempre possuem cunho pedagógico:

O meu estágio de anos iniciais foi bem impactante de forma ruim e isso refletiu de forma positiva na minha docência. (...) Não quero entrar em detalhes sobre isso mas a prática de ensino fundamental, que é o segmento que eu atendo hoje, foi traumática, aprendi muito o que "não" fazer (JF)

Revista Devir Educação, Lavras, vol.4, n.1, p.47-76 jan./jun., 2020. 


\section{OO DEVIR EDUCAÇÃO \\ ISSN: 2526-849X}

A situação acima não figura necessariamente como regra, podendo ser encarada como uma situação pontual infeliz de incompreensão das instituições e dos profissionais que receberam o estagiário. De fato, há uma série de comentários de experiências também positivas, tanto no que tange o estímulo dos professores na Universidade, quanto em relação aos professores regentes:

Penso muito no estágio de Séries Iniciais, que foram situações que me marcaram muito. Ter entrado com as crianças de um jeito, e ver depois de alguns meses como aquelas crianças tinham evoluído em termos de maturidade, comportamento e conhecimento. As dificuldades que iam se superando, ver a diferença que você é capaz de fazer na vida da pessoa. Uma pequena dica que pra você é corriqueira, mas que pro aluno leva pra vida inteira e muda o comportamento dele. (MS)

Outra característica desses estágios está no fato de que, embora sejam os momentos de contato com a prática docente, parece existir uma tendência em colocar os estudantes estagiários ainda como observadores da docência, não como praticantes em formação. Assim, observam a atuação profissional, mas não adquirem experiência ou prática. Tal relevo pode ser percebido no seguinte depoimento:

Nos estágios eu presenciei os professores lidando com as situações. Na extensão eu pude debater essas situações, refletir sobre elas com todo o grupo, pensar possibilidades e soluções, e como eu fui alfabetizadora na extensão pude, também, colocar em prática, muitas vezes, as soluções pensadas. Os estágios me deixavam mais como observadora, enquanto na extensão eu participava do processo de reflexão e de ação. $(\mathrm{CN})$

É possível perceber que as disciplinas de fundamentos teóricos da educação, que incluem os saberes das ciências da educação citados por Gauthier (1998) e a didática geral, correspondem a pouco mais de 1/4 da matriz curricular. Quando se retira as atividades complementares, pesquisa e TCC, então, para olhar apenas para as disciplinas, essa fatia fica ainda maior, constituindo pouco menos de 1/3 do curso (29,8\%). Em contrapartida, e de maneira 


\section{QO DEVIR EDUCAÇÃO \\ ISSN: 2526-849X}

equilibrada, os conhecimentos relativos à formação profissional específica, que incluem as práticas de ensino, totalizam outro terço do curso $(28,9 \%$, ou ainda $33,1 \%$, se desconsideradas as atividades complementares, pesquisa e TCC). Ora, se as disciplinas dessa natureza ocupam praticamente um terço das grades horárias, ocupando-se da formação docente em seu aspecto mais profissionalmente atuante, era de se esperar que permitisse uma aproximação maior com a cultura profissional. No entanto, não parece ser o que ocorre. Gatti (2010) esclarece que, da maneira como são estabelecidas, tais disciplinas aparentam ser insuficientes para a formação docente, devido justamente ao caráter teórico-abstrato das disciplinas que dizem respeito à pratica profissional propriamente dita.

Parece haver assim uma tendência na formação de professores em levar ao plano da teoria até mesmo o momento de prática. Tal afirmação leva ao extenso debate a respeito da desintegração entre teoria e prática no contexto da formação de professores. Ainda que essa questão seja extensamente discutida no campo da pesquisa educacional, Shulman (2004) afirma ser a tensão entre teoria e prática algo inevitável e essencial à formação profissional de um modo geral:

A característica central de qualquer formação profissional realmente é a tensão entre a teoria e a prática. É uma tensão essencial, tão inevitável quanto as tensões encontradas em famílias cujos membros tenham se tornado altamente dependentes uns dos outros. É uma tensão dolorosa porque teoria e prática não são apenas concepções competidoras. Diferentes interesses nos mundos social e político exercem controle sobre estes domínios, e qualquer preferência dada à teoria em vez da prática, ou à maestria conceitual em vez da proficiência técnica, por exemplo, terá sérias consequências para o futuro das instituições, a alocação de recursos escassos, e a conferência de valor e prestígio. (SHULMAN, 2004, p. 537).

Tal tensão, reconhecida nos depoimentos, deveria, de acordo com Nóvoa (2009), estar em equilíbrio no que diz respeito à estrutura curricular de cursos de formação de professores, uma vez que o modelo de estratificação entre teoria e prática vem demonstrando ser insuficiente e, portanto, longe do que considera ideal. Para o autor, a imersão na escola e o contato com professores mais experientes são fatores indispensáveis para adequada aprendizagem da docência: 


\section{OO DEVIR EDUCAÇÃO \\ ISSN: 2526-849X}

Ser professor é compreender os sentidos da instituição escolar, integrar-se numa profissão, aprender com os colegas mais experientes. É na escola e no diálogo com os outros professores que se aprende a profissão. O registo das práticas, a reflexão sobre o trabalho e o exercício da avaliação são elementos centrais para o aperfeiçoamento e a inovação. São estas rotinas que fazem avançar a profissão. (NÓVOA, 2009, p. 30).

Os depoimentos trazidos neste trabalho tendem a acordar com a impressão do autor: uma vez que enxergam nas disciplinas o lugar da teoria, e nos estágios das práticas de ensino o lugar da prática, transformar este segundo também no lugar da teoria, em detrimento da prática, é transformar o espaço escolar não num espaço de atuação, mas de observação e teorização. Embora de fato o seja, já que o locus escolar também é âmbito de pesquisa e produção de conhecimento, da maneira como aparece nas falas dos sujeitos, leva a compreender que a relação é de exclusão, já que a experiência de atuação dá lugar à experiência de observação passiva e abstração. Assim, embora o curso proporcione uma carga horária que privilegie a dimensão da prática, de maneira acentuada em relação ao recomendado pelas Diretrizes Curriculares Nacionais de Pedagogia (Resolução no 02/2015), que estabelece o mínimo de 400 horas dedicadas ao estágio supervisionado, de modo a favorecer a aproximação entre os estudantes e a profissão docente, parece falhar em suas intencionalidades - que se traduzem no que os depoentes colocam como um curso que, embora objetive o contrário, termina por privilegiar a teoria e negligenciar a prática, falhando assim em proporcionar de maneira significativa a aproximação entre os estudantes e a profissão docente.

Quando comenta sobre inexperiência em situações de tensão e descontrole em sala-deaula, AM traz a seguinte consideração:

Uma coisa que me fez parar para pensar, foi logo que entrei nessa escola. Sou contratada como mediadora, tiveram algumas vezes em que faltou professor e me mandaram substituir. Eu não sabia o que fazer. E pra minha surpresa, o que me salvou foi lembrar de quando eu era aluna, como os professores faziam, e foi o que acabei fazendo. Tanto a parte boa, sobre rotinas, as musiquinhas, quadro, brincadeiras, como a parte ruim, de gritar com eles quando perdia o controle, de passar atividades mais tradicionais, como desenhar com pontilhado, essas coisas. Foi como se eu não lembrasse de nada do que a Faculdade me ensinou. (AM)

Revista Devir Educação, Lavras, vol.4, n.1, p.47-76 jan./jun., 2020. 


\section{Q DEVIR EDUCAÇÃO \\ ISSN: 2526-849X}

Ao perceber as práticas de ensino, não como experiências de atuação profissional, e sim de observação e teorização, e por este motivo as perceberem como experiências teóricas, AM parece ter encontrado dificuldades em relacionar o vivido - e, mais enfaticamente, observado - nos estágios, com possíveis estratégias de ensino e de gestão de sala-de-aula. Então, recorreu à única experiência vivida que percebeu como vivências em sala: suas próprias trajetórias escolares enquanto discentes. A esse respeito, JF comenta:

Quando cheguei à sala de aula, eu não me lembrava de nada que havia estudado, deu branco, e nesses casos recorremos as vivências. Eu tinha duas vivências: uma como aluna e outra com o PIBID, e foi essa que me salvou, se não eu teria reproduzido tudo o que os meus professores da escola fizeram e não concordo com grande parte. (JF)

Quando afirma que só possuía duas vivências em sala-de-aula, uma enquanto discente escolar, e outra no contexto do PIBID, JF também dá a entender não ter percebido os momentos dos estágios como vivências práticas. A tendência a recorrer à experiência de aluna, no entanto, foi suprimida pela experiência de aprendizagem da docência vivida no contexto do PIBID.

O PIBID é um programa de iniciação à docência de parceria entre universidade e escola, com o objetivo de favorecer a aprendizagem da docência. A parceria envolve um professor orientador na Universidade e um professor supervisor na escola, que juntos trabalham desenvolvendo estratégias de aprendizagem da docência. Na escola, os alunos acompanham professores experientes e desenvolvem atividades junto a eles; na universidade, as trocas entre pares sob a orientação de um professor favorecem as problematizações e a construção de conhecimento, favorecendo o desenvolvimento de uma postura crítica e reflexiva acerca da própria prática, permitindo o rompimento da desfragmentação entre teoria e prática, de modo que tornem-se estas indissociáveis - facetas complementares da atuação profissional docente.

Dentre os sujeitos, JF, FL e CF são aqueles cujas falas destacam-se em relação às demais: ambos consideram-se professores e, apesar de trazerem considerações sobre a formação, reconhecem nela elementos que permitiram aproximação tal com a docência que foi possível atuar em sala de aula sem maiores dificuldades além daquelas inerentes à inserção profissional. JF e FL foram bolsistas do PIBID, enquanto CF participou de um projeto de 


\section{Q DEVIR EDUCAÇÃO \\ ISSN: 2526-849X}

extensão (PIBEX) de alfabetização de Jovens e Adultos. Em diversos momentos de seus depoimentos, todas as três reconhecem ter sido este o fator diferencial em sua formação:

Mas o que identifico mesmo como o diferencial foi o PIBID, porque justamente, por propor essa associação entre teoria e pratica, escola e universidade, o que os estágios não me proporcionaram muito. (FL)

Quando estou em sala de aula, o que mais recorro é ao PIBID (...) O PIBID sem sombra de dúvida me ajudou a construir um olhar para a criança que está ali aprendendo, que é um ser humano, um ser pensante, criativo... E me fez considerar todas essas coisas em sala de aula. (JF)

Todo o meu movimento na graduação foi importante. Mas posso dizer com certeza que a Extensão teve um papel fundamental no meu "ser professora". Por me permitir atuar, experimentar o fazer docente antes mesmo de concluir a graduação. E com respaldo, com estrutura emocional e pedagógica. $(\mathrm{CN})$

O PIBID, tanto da Educação Infantil quanto do Ensino Fundamental, juntamente ao PIBEX no relato de $\mathrm{CF}$, apareceram como os contextos mais mencionados nos quais os sujeitos puderam experimentar a cultura profissional ao longo da graduação. No relato de DZ, no entanto, sua participação no PIBEX parece não ter apresentado contribuição para a formação docente:

No projeto de extensão, eu trabalhava como uma secretária. Era um projeto da PR1 ou PR2, não lembro, de iniciação científica de ensino médio. Aí eu servia de contato entre os grupos de pesquisa e os estudantes, cadastrando, enviando notificações, essas coisas. Então acho que não teve influência nenhuma. (DZ)

MS traz considerações da mesma natureza acerca da Monitoria. Tendo sido selecionada para o quadro de sujeitos justamente pela experiência neste contexto, ela sequer o mencionou até que fosse especificamente questionada.

Sinceramente, não teve impacto nenhum e isso até me decepcionou, porque eu comecei um outro curso antes da Pedagogia, e nele a ideia de monitoria é diferente. Não cheguei a ser monitora lá, mas todas as disciplinas tinham

Revista Devir Educação, Lavras, vol.4, n.1, p.47-76 jan./jun., 2020. 


\section{Q DEVIR EDUCAÇÃO \\ ISSN: 2526-849X}

monitor e eles não eram só um "assistente" do professor para ligar o datashow, carregar peso, pegar café e levar texto para a xerox, como foi a minha experiência na FE. Os monitores lá tinham que fazer aulas de monitoria, que eram aulas extras fora do horário de aula, nas quais ele dava aulas e tirava dúvidas e ficava à disposição dos alunos, e era ele o responsável pelas aulas de revisão antes das provas. Então a pessoa de fato ensinava. Tive monitores lá e por isso procurei a monitoria na FE. O que descobri é que é uma contradição. Na FE, que forma professores, que é onde essa característica de aprender a ensinar deveria em tese ser mais forte, eu era como uma assistente da professora, mas o sentido de fazer favores. Faz-tudo, sabe? A parte que eu fazia que mais tinha a ver com a docência era passar a lista de chamada e depois passar para a pauta de frequência. Fora isso, eu era alguém que a professora mandava pra lá e pra cá, que pegava lista de email dos alunos e passava pro computador, essas coisas. Tenho colegas que eram obrigados a ir buscar lanche pro professor, buscar café na copa, essas coisas. Quase um assistente pessoal. (MS)

Outro contexto que pouco apareceu nas falas dos depoentes foi o PIBIC. A participação em grupos de pesquisa não apareceu na fala dos depoentes como um fator significativo de aprendizagem da docência ou de contato com a cultura profissional. A seu respeito, trouxeram os entrevistados:

Pesquisa também te ajuda a entender, mas não a fazer. (AM)

A pesquisa, acho que me ajudou a criar uma atitude de problematização e reflexão, e me ajudou a estudar. A pesquisa me ensinou a buscar e selecionar informações, a elaborar conhecimento. Então me ajuda a organizar, sistematizar e compreender meu próprio conhecimento sobre a docência, mas em termos de prática, não acho que tenha influenciado. (DZ)

Em relação ao Centro Acadêmico, foram integrantes do movimento DZ e FL. Embora reconheça ter contribuído especificamente para sua formação como pedagoga, conforme depoimento acima, FL o comenta apenas de forma vaga, deixando claro que esta influência não diz respeito à formação docente em si. Curiosamente, no caso de DZ, esta o reconhece como fator que mais a aproximou da docência, ao ensinar sobre a Universidade, e, portanto, a cultura acadêmica, aos estudantes recém-ingressos. Assim, ensinar a cultura acadêmica a permitiu aproximar-se da cultura profissional:

Revista Devir Educação, Lavras, vol.4, n.1, p.47-76 jan./jun., 2020. 


\section{OO DEVIR EDUCAÇÃO \\ ISSN: 2526-849X}

Os momentos em que participei do Centro Acadêmico e tinha que puxar alguma atividade, principalmente na calourada, de estar ali conversando com os calouros e vivenciando a faculdade, me senti um pouco docente, porque tava passando conhecimento da universidade para eles, conhecimentos básicos, de rotina, foi ali mais ou menos que senti que estava vivendo uma relação de esino. (DZ)

As divergências entre sujeitos que transitaram em um mesmo âmbito e que o percebem de maneiras diferentes, parecem sugerir que a diferença está na natureza e nos objetivos dos programas/projetos/contextos frequentados, assim como sua aproximação ou afastamento em relação ao âmbito de atuação profissional.

Quando Shulman (2005) comenta que a aprendizagem de uma profissão envolve três dimensões distintas - o pensar, o atuar e o agir com integridade -, e que em geral os cursos de formação inicial tendem a privilegiar pelo menos duas destas dimensões, frequentemente negligenciando ou tratando de forma tangencial a terceira, pode parecer uma generalização. No caso do contexto investigado, no entanto, sua previsão parece se concretizar, de modo que, após analisadas as entrevistas, é possível afirmar que, junto do pensar - a dimensão onde se estabelece o processo adequado de raciocínio no que diz respeito ao fazer profissional -, o curso de Pedagogia investigado enfatiza também a dimensão do atuar, que diz respeito à prática propriamente dita, à atuação profissional, muito embora as inferências deixem perceber que tal ênfase, que aparece especialmente pronunciada no PPC do curso e se expressa nas escolhas curriculares que compõem a sua estrutura, nem sempre ocorra da maneira como o currículo preconiza.

Tais afirmações são possíveis a partir das falas dos estudantes, conforme discutido nos eixos já apresentados: os sujeitos reconhecem ser o contexto investigado, um curso de currículo predominantemente disciplinar, focando nos saberes relacionados à Educação em suas diversas dimensões, concepções e abordagens, nos procedimentos pedagógicos envolvidos no processo de ensino-aprendizagem; cuja força formativa se transforma em fraqueza ao propor uma matriz curricular essencialmente, e portanto, excessivamente disciplinar, organizada de tal maneira a limitar as possibilidades de trânsito em outros âmbitos acadêmicos que favoreceriam o contato com o campo de atuação e, portanto, com a cultura profissional; que, apesar da ênfase disciplinar e, portanto, teórica, reconhece a importância e o lugar da prática docente, extrapolando em aproximadamente $266 \%$ a carga horária de estágio recomendada pelas DCN

Revista Devir Educação, Lavras, vol.4, n.1, p.47-76 jan./jun., 2020. 


\section{Q DEVIR EDUCAÇÃO \\ ISSN: 2526-849X}

do curso de Pedagogia. Tal esforço, no entanto, esbarra na questão de o aluno, no momento de estágio, por vezes ocupar um lugar de observação, e não de atuação. No entanto, embora recorrente nos depoimentos dos sujeitos entrevistados, esta parece ser uma tendência que está ligada muito mais à dimensão do agir com integridade por parte dos professores formadores, do que de desvalorização do momento de atuação, uma vez que a PPC deixa claro o esforço em proporcionar a experiência de imersão na prática dentro do contexto dos estágios.

As experiências de estágio relatadas como tendo impacto positivo na aprendizagem da docência são aquelas nas quais o professor da Universidade oferece orientação e respaldo para as questões advindas do contexto do estágio; e o professor da turma regente que os recebe na escola demonstra preocupação com a aprendizagem da docência dos estagiários, oferendo também orientação e a oportunidade de experiência de atuação. Tais atitudes envolvem elementos que Silva, Almeida, Gatti (2016) entendem como o engajamento profissional: as concepções de sociedade, sujeito, e especialmente de docência, que envolvem as dimensões éticas, filosóficas e políticas da constituição identitária profissional, e que Shulman (2005) denomina agir com integridade. Uma vez que esta dimensão apareça como uma vulnerabilidade no tocante à aprendizagem da docência, tendo, de acordo com os depoimentos, impacto direto na aprendizagem da docência e na constituição identitária docente dos estusantes, bem como em sua percepção acerca da profissão e, portanto, a relação que com ela desenvolve, pode-se observar que, privilegiando as dimensões do pensar a profissão, e atuar na profissão, aparenta haver uma certa tendência a tangenciar, na formação de professores do curso, a dimensão do agir com integridade, de modo que a preocupação com a aprendizagem de conhecimentos a serem mobilizados no ato do ensino, e os processos adequados de raciocínio docente, junto de uma imersão na observação da prática, apareçam, a partir de depoimentos dos sujeitos da pesquisa, como as principais marcas pedagógicas do curso analisado.

\section{Considerações finais}

A partir dos dados levantados nesta pesquisa, foi possível observar que, dentre as dimensões propostas por Shulman (2004) para uma formação profissional - pensar, atuar e agir com integridade - o curso de Pedagogia investigado, na visão dos entrevistados, prioriza

Revista Devir Educação, Lavras, vol.4, n.1, p.47-76 jan./jun., 2020. 


\section{QO DEVIR EDUCAÇÃO \\ ISSN: 2526-849X}

os dois primeiros, que em Silva, Almeida, Gatti (2016) aparecem como conhecimento profissional e prática profissional, havendo um tangenciamento da dimensão que Silva, Almeida, Gatti (2016) denominam engajamento profissional, e que Shulman (2004) chama de agir com integridade.

Embora a dimensão do atuar, que figura a dimensão da própria prática profissional, demonstre ser uma preocupação do curso investigado, esta não se traduz no entanto numa aproximação real entre os estudantes e a cultura profissional, uma vez que o estágio, enquanto lugar da prática figura predominantemente como âmbito de observação, e não de atuação profissional. O não-reconhecimento do momento do ensino disciplinar, por parte dos professores formadores, como um momento também de ensino da docência a partir da própria prática, demonstra assim uma tendência ao tangenciamento da dimensão ética, política e filosófica da docência: o engajamento profissional, ou como coloca Shulman (2004), o agir com integridade. A ênfase no pensar e no atuar, ainda estruturados de tal maneira que uma dimensão seja mais evidenciada que a outra, envolve uma tensão que tem sido objeto de debates no campo da formação de professores, e aparece com frequência na fala dos sujeitos aqui entrevistados: a desintegração entre teoria e prática, e o afastamento entre universidade e escola.

Os achados deste trabalho contribuem para a compreensão acerca dos desafios e problemas relacionados a uma formação inicial docente, que proporcione elementos indispensáveis e contributivos à aprendizagem da docência. Há que se observar a noção de Cochran-Smith (2012), de que a aprendizagem da docência não se dá apenas no momento formativo inicial, mas ao longo de toda a vida profissional - o que, longe de justificar a existência de fragilidades na formação inicial, implica em um projeto de formação que ensine não apenas conhecimentos importantes acerca da docência, mas o desenvolvimento de uma postura sobre a docência que implique a compreensão da necessidade de estar em permanente processo de aprendizagem.

Este trabalho ajuda na compreensão da própria concepção de aprendizagem da docência, e das estruturas dos cursos de formação inicial de professores, especialmente no contexto investigado; e serve também de base para novos estudos a partir das questões aqui levantadas, entre elas: Como proporcionar uma formação inicial docente adequada, em um curso que possui a responsabilidade de formar estudantes de pedagogia para as diversas áreas de atuação? E como estabelecer uma estrutura curricular que equilibre a ênfase nas diferentes 


\section{Q DEVIR EDUCAÇÃO \\ ISSN: 2526-849X}

dimensões de ensino da profissão docente? Como conceber um curso de formação inicial de professores, que aproxime de maneira adequada os estudantes de sua cultura profissional?

\section{Referências}

BRASIL. Conselho Nacional de Educação. Conselho Pleno. Parecer no 2/2015. Diretrizes Curriculares Nacionais para a Formação Inicial e Continuada dos Profissionais do Magistério da Educação Básica. Brasília, DF: CNE, 2015a.

Projeto Pedagógico de Curso do Curso de Licenciatura em Pedagogia. Faculdade de Educação. Rio de Janeiro, RJ. Disponível em http://www.educacao.ufrj.br/wpcontent/uploads/2019/08/PPC-atualizado-2014-2015.pdf> Acesso em 19 Nov. 2019.

COCHRAN-SMITH, M. A tale of two teachers: Learning of teach over time. Kappa Delta pi Record, Boston: p. 108-122, jul./set. 2012.

ERIKSON, E. H. Infância e Sociedade. $2^{a}$ ed. Rio de Janeiro: Zahar editores, 1987.

GATTI, B. A. Formação de professores no Brasil: características e problemas. Educ. Soc., Campinas, v. 31, n. 113, p. 1355-1379, dez. 2010.

GAUTHIER, C. et al. Por uma teoria da pedagogia: pesquisas contemporâneas sobre o saber docente. 2 ed. Ijuí: Ed. Unijuí, 1998.

NOVOA, A. Para uma formação de professores construída dentro da profissão. Revista de Educación, Lisboa: n. 350, p. 203-218, set./dez. 2009.

SHULMAN, L. The Whisdom of Practice: Essays on Teaching, Learning and Learning to Teach. San Francisco: Jossey-Bass, 2004.

SHULMAN, L. Signature pedagogies in the professions. Cambridge: Dedalus, p. 52-59, 2005.

SILVA, V.; ALMEIDA, P.; GATTI, B. Referentes e critérios para a ação docente. Cadernos de Pesquisa, São Paulo, v. 46, n. 160, p. 286-311, abr./jun. 2016.

Recebido em: 18/06/2019.

Aprovado em: 10/10/2019.

Revista Devir Educação, Lavras, vol.4, n.1, p.47-76 jan./jun., 2020. 